\title{
1 O PAPEL DO ENFERMEIRO NA SEXUALIDADE DO CIDADÃO COM PROBLEMAS NO SEU "CONTINUUM DE SAÚDE"
}

Hélder Lourenço ${ }^{1} \mid$

O que é a sexualidade? A resposta a esta questão não é simples. Freud observava a sexualidade como uma força psicológica e biológica fundamental para a estruturação da personalidade (Masters, Johnson \& Kolodny, 1987; Brandão, 2007), ou seja, o conceito de sexualidade assume-se mais como um processo com que o ser humano se estrutura, organiza e comunica, sendo igualmente uma expressão física e emocional poderosa, estruturante da psique humana e da organização social, conforme é assinalado por vários autores (Nunes, 1987; Foucault, 1994; Alberoni, 2007). Estas considerações sobre a sexualidade humana são essenciais para se conseguir definir, entender ou operacionalizar a saúde sexual, que é definida pela Organização Mundial de Saúde (cit. por Oliveira, 2014, p. 37) como: “...um estado de bem-estar físico, mental e social em relação à sexualidade. Exige uma abordagem positiva e de respeito pela sexualidade e relações sexuais, bem como a possibilidade de ter experiências sexuais agradáveis e seguras, livre de coerção, discriminação e violência”.

Assim, a sociedade, para se tornar sexualmente saudável, deve aceitar os desafios de reconhecer que a saúde sexual é um direito humano fundamental, que devem existir políticas públicas para a sua promoção e proteção, que devem existir leis que protejam os direitos sexuais, que deve existir acesso universal a uma cuidada educação sexual adequada à idade, que deve existir um acesso também a serviços de saúde equipados com profissionais especializados e à vigilância e monitorização adequada de comportamentos e indicadores de saúde sexual. Neste sentido, a saúde sexual não deve limitarse apenas ao aconselhamento e cuidados de saúde relativamente à procriação e ao evitamento das doenças sexualmente transmissíveis, mas também constituir uma abordagem positiva à sexualidade humana para o enriquecimento da vida e das relações interpessoais (Barros \& Figueiredo, 2014). culturais, legais, históricos, religiosos e espirituais) e requer sempre um estudo multidisciplinar e multiprofissional para uma correta intervenção em contexto de saúde. Idealizar uma intervenção em saúde sexual requer organizar as respostas e os cuidados de saúde tendo como linha orientadora o ciclo de vida e as múltiplas transições vividas, nomeadamente nos processos de saúde/doença, que não se coadunam com protocolos de atuação e tratamento específicos de uma única problemática ou circunscritos a uma única profissão ou especialidade.

A forma como planeamos os cuidados na área da saúde sexual ao longo destes processos transacionais do ciclo da vida requer a desconstrução de mitos e representações erróneas sobre o género e o sexo, que definitivamente têm que aglutinar as dimensões biológicas, humana e social, assim como integrar os novos conhecimentos da sexualidade humana na formação e no desenvolvimento dos profissionais de saúde.

Sempre que o "continuum" de saúde é quebrado, a dimensão sexual é igualmente abalada, requerendo uma preocupação acrescida na sua promoção, prevenção e identificação da problemática acometida, obrigando os profissionais de saúde, nomeadamente o enfermeiro, como elo essencial da equipa multidisciplinar e fulcral na prestação de cuidados, a defender a privacidade e a intimidade da pessoa doente ou com restrições de qualquer ordem, seja ao nível dos cuidados primários, diferenciados ou continuados.

$\mathrm{Na}$ presença de um problema sexual são frequentes os sentimentos de dúvida e medo por parte da pessoa, manifestando enorme dificuldade em abordar este problema com os profissionais de saúde por pensar que é desadequado para a situação, ou mesmo por timidez, ou até por achar que tem que ser o profissional de saúde a determinar quando esta problemática deve ser focada.

\footnotetext{
1 Sexólogo Clínico e Terapeuta Sexual pela Sociedade Portuguesa de Sexologia Clínica; Secretário da Mesa do Colégio da Especialidade de Enfermagem de Saúde Mental e Psiquiátrica da Ordem dos Enfermeiros (mandato 2020-2023); Enfermeiro especialista em Enfermagem de Saúde Mental e Psiquiátrica no Centro Hospitalar Tondela Viseu, EPE, Unidade de Saúde Mental Comunitária, Avenida Rei Dom Duarte, 3504-509 Viseu, Portugal, helderacfl@gmail.com
}

Citação: Lourenço, H. (2020). O papel do enfermeiro na sexualidade do cidadão com problemas no seu "continuum de saúde". Revista Portuguesa de Enfermagem de Saúde Mental (23), 06-08. 
No entanto, estranhamente e não raras vezes, o mesmo acontece por parte dos profissionais de Enfermagem, que maioritariamente demonstram também uma enorme dificuldade em lidar com esta área da expressão sexual, fazendo imperar o silêncio como forma de resolução desta problemática (Wimberly \& Moore, 2007). Os cuidados de Enfermagem tomam sempre por foco de atenção a promoção dos projetos de saúde de cada cidadão, independentemente da sua raça, credo ou género, e neste contexto procuram sempre, ao longo do ciclo vital, prevenir a doença e promover os processos de readaptação, procurar a satisfação das necessidades humanas fundamentais e a máxima independência na realização das atividades de vida, ao mesmo tempo que procuram a adaptação funcional aos défices e a adaptação a múltiplos fatores. Neste sentido, a sexualidade e as suas alterações terão que ser sempre objeto, e ou mesmo tempo objetivo, destes padrões de qualidade dos cuidados de Enfermagem e dos seus enunciados descritivos (Ordem dos Enfermeiros, 2012).

A chave para se poder providenciar ajuda no plano sexual das pessoas está precisamente na capacidade que o enfermeiro terá em abordar o tópico sexual, de espírito aberto e através da escuta ativa, com a indispensável isenção de juízos de valor, mantendo sempre a neutralidade mas sabendo reconhecer os seus próprios receios ou limitações (éticas ou religiosas), tratando a sexualidade como abordaria qualquer outro assunto da saúde e de preferência num ambiente descontraído, mas utilizando um espaço físico que respeite a dignidade e a confidencialidade das pertinentes questões sexuais, providenciando assim uma discussão e capacitação serena do utente (Mercadier, 2002).

Cada vez mais os profissionais de saúde estão atentos à temática da sexualidade humana, de tal forma que já existem várias valências ligadas a esta área, tais como a medicina sexual e a sexologia clinica, que se encontram em franca expansão mundial e em Portugal, abrangendo uma multiplicidade de profissionais tais como enfermeiros, médicos, psicólogos e farmacêuticos, entre outros, que permite abordar e intervir nas pessoas que necessitem de ajuda especializada nesta necessidade humana básica, com melhores resultados se o fizerem de forma conjunta e organizada.

Acredita-se que a existência de equipas especializadas em saúde sexual, multidisciplinares e com a participação ativa de vários profissionais, onde o enfermeiro especialista em Enfermagem de Saúde Mental e Psiquiátrica poderá e deverá ter um papel fundamental, quer pelas suas competências especificas, quer pelas suas potenciais competências acrescidas obtidas na área especifica da sexologia humana (educacional e clinica), serão essenciais para o desenvolvimento clinico diferenciado, dando resposta às situações de maior complexidade e diferenciação, devendo igualmente fazer um trabalho de consultadoria com outras equipas e áreas específicas.

No entanto, é impreterível, no primeiro contacto com o profissional de saúde que acolhe a pessoa doente ou com restrição da participação e que a acompanha durante todo o processo de internamento e posterior recuperação e reabilitação (quase sempre o Enfermeiro), criar uma relação empática, de compromisso, e sobretudo profissional, basilar e essencial para debelar a sexualidade protegida e promover uma cidadania sexual saudável e proativa, numa área da saúde quase sempre esquecida, negligenciada, onde não abundam os recursos humanos e materiais, sendo que aqueles que existem são muitas vezes inatingíveis para pessoas com baixos rendimentos (raramente existindo comparticipação estatal) e muito pouco divulgados pelos profissionais de saúde que os assistem, levando a que esta necessidade humana básica seja por vezes estranhamente esquecida e não priorizada.

\section{REFERÊNCIAS BIBLIOGRÁFICAS}

Alberoni, F. (2007). Sexo e Amor (2a ed.). Lisboa: Bertrand Editora.

Barros, F., \& Figueiredo, R. (2014). Manual de medicina sexual: Visão multidisciplinar. Lisboa: Menarini Portugal.

Brandão, A. (2007). A problemática da sexualidade humanizada: Sexoterapia ou reequilíbrio humano?. Loures: Lusociência.

Foucault, M. (1987). A arqueologia do saber (3a ed.). Rio de Janeiro: Editora Forense Universitária.

Masters, W., Johnson, V., \& Kolodny, R. (1987). Amour sexualite: Mieux vivre sa vie sexuelle dans le monde d'aujourd'hui. Paris: InterEditions.

Mercadier, C. (2002). O trabalho emocional dos prestadores de cuidados em meio hospitalar. Loures: Lusociência 
Nunes, C. (1987). Desvendando a sexualidade (4a ed.). Campinas: Papirus.

Oliveira, F. R. (2014). Saúde sexual. In F. Barros, \& R. Figueiredo (Eds.), Manual de medicina sexual: Visão multidisciplinar. Lisboa. Menarini Portugal.
Ordem dos Enfermeiros. (2012). Padrões de qualidade dos cuidados de enfermagem: Enquadramento conceptual e enunciados descritivos. Lisboa: Ordem dos Enfermeiros.

Wimberly, Y., \& Moore, S. E. (2007). Doctors, patients, and sexuality. In G. Herdt \& C. Howe (Eds.), 21st century sexualities: Contemporary issues in health, education and rights (pp. 92-95). Londres: Routledge.

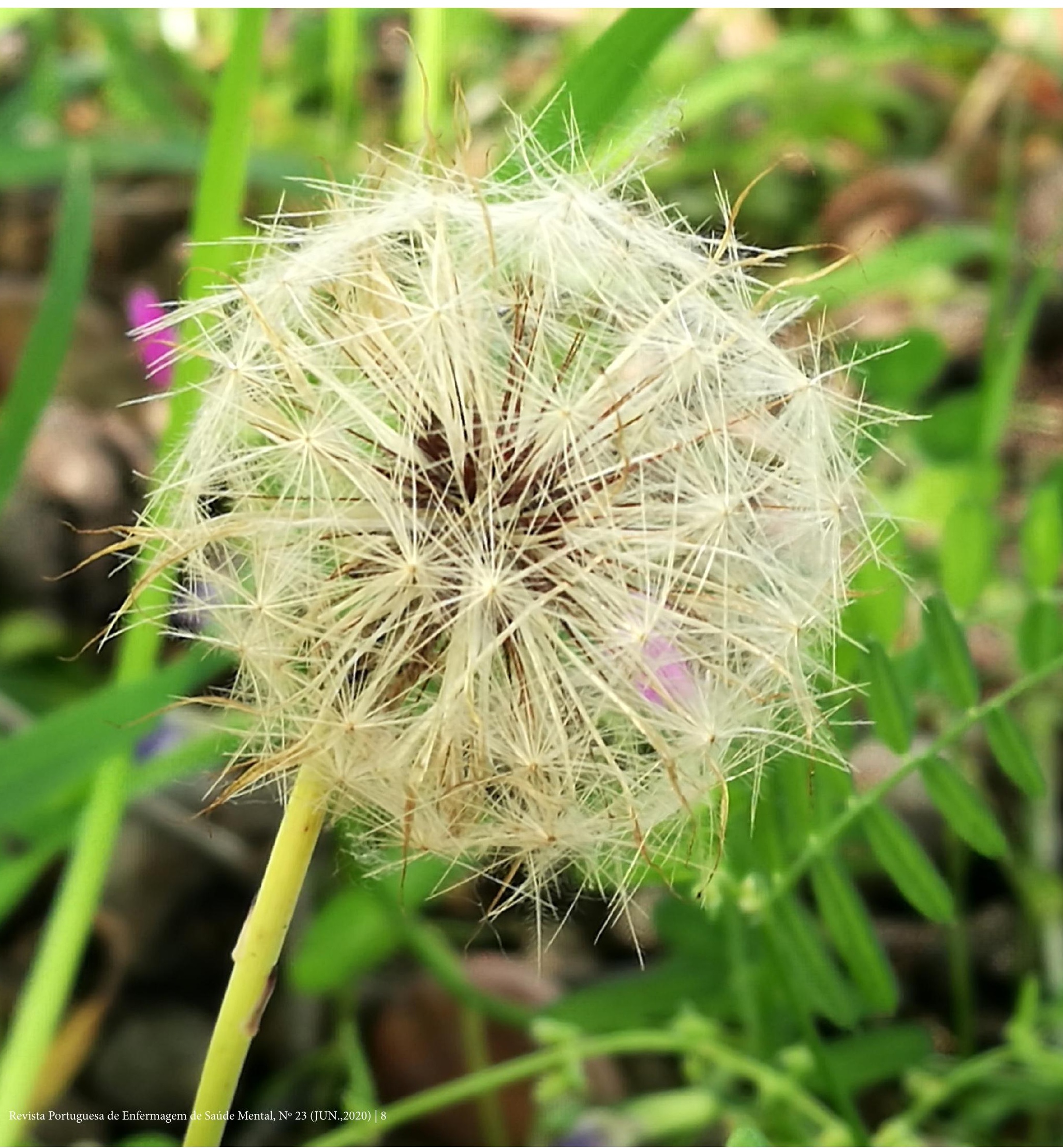

